\title{
Adaptação do Indicador de Salubridade Ambiental (ISA) como ferramenta de análise da salubridade do ambiente da Comunidade Saramém-Brejo Grande/SE
}

Adaptation of Indicator of Environmental Salubrity (ISA) as an analytical tool of the environmental salubrity of the Community Saramém-Brejo Grande/SE

\author{
M. M. Albuquerque ${ }^{1 *} ;$ J. Daltro Filho $^{2}$ \\ ${ }^{I}$ Departamento de Desenvolvimento Urbano, Prefeitura Municipal de Aracaju, 49.097-270, Aracaju-Sergipe, Brasil \\ ${ }^{2}$ Departamento de Engenharia Civil, Universidade Federal de Sergipe, 49.100-000, São Cristóvão- Sergipe, Brasil
}

*mm_albuquerque@hotmail.com

(Recebido em 10 de junho de 2015; aceito em 29 de outubro de 2015)

\begin{abstract}
Foi elaborado um estudo sobre a salubridade ambiental da comunidade rural Saramém, no município de Brejo Grande no Estado de Sergipe, tendo como objetivo principal a análise da influência da salubridade ambiental em seu conjunto habitacional e em sua população, através da adaptação do Indicador de Salubridade Ambiental (ISA). Denominado aqui de ISA/SAR, o indicador utilizou os seguintes subindicadores: Sub-Indicador de Abastecimento de água, Sub-Indicador de Esgotamento Sanitário, SubIndicador de Resíduos Sólidos, Sub-Indicador de Saúde Pública, Sub-Indicador de Características da Moradia, Sub-Indicador de Satisfação com a Moradia e o Entorno, Sub-Indicador de Espaço Público Comunitário e Sub-Indicador Sócio-Econômico. Os dados utilizados foram coletados em campo, segundo diferentes fontes: em uma amostra dos domicílios da comunidade e em órgãos públicos municipais e estaduais. A partir dos resultados, verificou-se que a rede de infraestrutura de saneamento ambiental existente na comunidade Saramém produz um ambiente com baixa salubridade, afetando assim a saúde de sua população.
\end{abstract}

Palavras-chave: Desenvolvimento Sustentável, Indicador de Salubridade ambiental, Saneamento e Salubridade Ambiental

Was elaborated a study about the environmental salubrity of the rural community Saramém, in the town of Brejo Grande in the state of Sergipe, having as main objective the analysis of the influence of environmental salubrity in its housing and its population, by adapting the Indicator of Environmental Salubrity - ISA. Denominated here as ISA / SAR, the indicator used the following sub-indicators: SubIndicator of Water Supply, Sub-indicator of Sanitary Sewage, Sub-Indicator of Solid Waste, SubIndicator of Public Health, Sub-Indicator of House Characteristics, Sub-Indicator of Housing Satisfaction and Neighborhood, Sub-Indicator of Communitarian Public Space and Sub-Indicator Socio-Economic. The data used were collected in the field by different sources: in a sample of households in the community and state and local public organs. From the results, it was found that the infrastructure network of environmental sanitation existing in the community Saramém produces an environment with low health, affecting thus the health of its population.

Keywords: Sustainable Development, Indicator of Environmental Salubrity and Sanitation and Environmental Salubrity

\section{INTRODUÇÃO}

O complexo panorama atual acerca das questões ambientais reflete no meio urbano assim como no rural, alterando suas dinâmicas e impactando de modo agressivo e acelerado no ambiente. Há uma constante situação de insalubridade nas cidades, quer seja nas periferias e comunidades menos abastadas e longínquas dos grandes centros urbanos, quer seja na população rural comumente dispersa e que, habitualmente, não têm acesso aos serviços mínimos de saneamento ambiental, tais como abastecimento de água e esgotamento sanitário. Estas e várias outras deficiências devem-se a própria rapidez com que o processo urbano ocorreu no país aliado à ausência de um sistema de planejamento urbano eficaz (AFONSO, 2006)[1] .

O saneamento ambiental surge, portanto como forma de contribuir com a manutenção do equilíbrio da natureza e, deste modo, com a própria sobrevivência humana e de todos os 
recursos a esta indispensáveis (OLIVEIRA; CARVALHO, 2007)[4], assegurando deste modo a própria saúde do ambiente e da população assim como uma vida de qualidade agora e para as futuras gerações.

No entanto, se nos grandes núcleos urbanos ainda há enorme dificuldade de levantamento de dados nesta área, nas áreas rurais, por sua vez, esta dificuldade é ainda maior. Os principais entraves encontrados devem-se ao acesso aos serviços de infraestrutura de saneamento ambiental se dar de forma irregular e insatisfatória em tais localidades; há também ausência de informações e dados técnicos de levantamento sobre a demanda existente e a capacidade de suporte da infraestrutura instalada como de estudos referentes à qualidade dos serviços prestados. Para assegurar este acesso aos serviços de saneamento, é necessário compreender que desenvolvimento é também "apropriação efetiva de todos os direitos humanos, políticos, sociais, econômicos e culturais" (SACHS, 2000, p.60) [6], inclusive ao direito coletivo que se tem ao meio ambiente e, portanto a oferta de serviços públicos de qualidade.

Para tal, há um grande interesse pela composição e utilização de sistemas de indicadores especialmente o Indicador de Salubridade Ambiental (ISA) elaborado pelo Conselho Estadual de Saneamento (CONESAN) do Estado de São Paulo - que atuam como importante instrumento de auxílio à gestão nas várias esferas, tanto no âmbito rural quanto nas cidades, uma vez que revelam as mais variadas informações, contribuindo assim para a tomada de decisões do setor público e também privado.

Há uma série de estudos contemplando a utilização do ISA em outros estados e regiões do Brasil, principalmente em virtude de sua adaptabilidade ao contexto em que ocorre. Para tal, foram estudados quatro principais modelos derivados do ISA original: ISA/F, aplicado a favelas localizadas em áreas de proteção aos mananciais em São Paulo/SP, elaborado por Almeida e Abiko (2000); ISA/OE aplicado a áreas de ocupação espontânea em Salvador/BA, elaborado por Dias (2003); ISA/JP aplicado a bairros costeiros na cidade de João Pessoa/PB, elaborado por Batista e Silva (2006) e ISA, elaborado por Menezes (2007), por sua vez, não modificou a nomenclatura mas realizou algumas alterações no modelo original para sua aplicação em comunidades carentes de Minas Gerais.

Dado o exposto, optou-se por objeto de estudo a comunidade pesqueira do Saramém, localizada na área rural do município de Brejo Grande no Estado de Sergipe, com o objetivo de analisar a influência da salubridade ambiental em seu conjunto habitacional e em sua população, através da adaptação do Indicador de Salubridade Ambiental (ISA). Apesar de sua configuração inicial se dar de forma espontânea e natural (Figura 1a), a localização do atual Saramém se deu desde o início de maneira ordenada e com características urbanas (Figura1b), mas que ainda assim apresenta uma grande deficiência de atributos inerentes a uma vida saudável no local tais como saneamento ambiental adequado, equipamentos e até mesmo serviços urbanos.
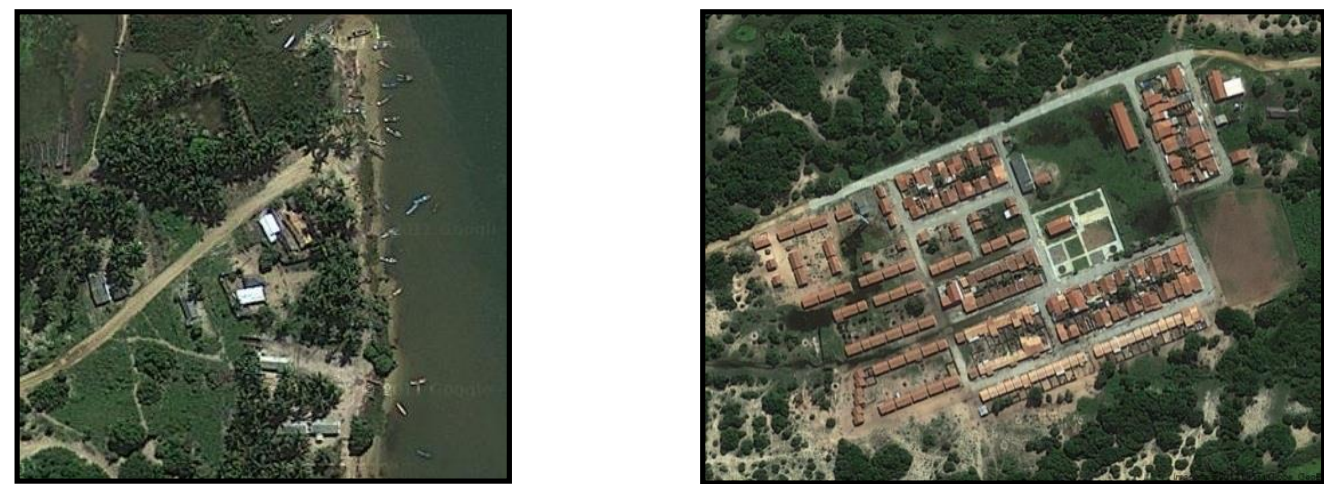

Figura 1: Configuração espacial do antigo porto (a) e da atual comunidade Saramém (b).

Fonte: Google Maps (2012).

Desde a criação do conjunto que então abriga esta comunidade, várias populações alheias sentiram-se incentivadas a fixar residência nesta nova configuração sócio-espacial, sem apresentar características semelhantes com seu modo de vida. Isto aliado à inadequação dos serviços de infraestrutura de saneamento ambiental, torna-se determinante para a salubridade do ambiente bem como para a qualidade de vida destes ribeirinhos. 


\section{MATERIAL E MÉTODOS}

Para o do referido trabalho, optou-se pela adoção do Indicador de Salubridade Ambiental como forma de avaliar a salubridade ambiental da comunidade estudada.

A metodologia foi alimentada por meio de coleta de dados primários em campo com uma amostra da comunidade (um total de 44 domicílios pesquisados, através de amostragem probabilística aleatória simples), e de dados secundários em campo com consulta a órgãos públicos municipais (Prefeitura Municipal, Secretaria Municipal da Saúde, Secretaria Municipal de Educação, Secretaria Municipal de Ação Social), e estaduais (a exemplo da Companhia de Saneamento de Sergipe - DESO). Ambas as coletas primárias e secundárias foram realizadas através da aplicação de formulários com perguntas estruturadas segundo definição tanto das variáveis quanto dos parâmetros do ISA/SAR.

Além disto, houve levantamento de dados por meio de observação in loco de demais fatores que influenciam e caracterizam o objeto de estudo.

Todo o trabalho em campo foi realizado durante o período de janeiro a junho de 2012, com visitas periódicas de 15 (quinze) em 15 (quinze) dias.

Após os questionários aplicados e as observações in loco, os dados foram identificados, organizados e analisados de forma a servir ora para a conscientização da comunidade como importante subsídio para futuras pesquisas por parte dos órgãos competentes quanto à necessidade e o direito de um saneamento ambiental de qualidade aliado a uma gestão integrada e eficaz que se deseja para cidades e municípios. Nesse sentido, foram captados oito subindicadores utilizados para a composição do Indicador de Salubridade Ambiental do Saramém o ISA/SAR - aqui a serem discutidos, a saber:

- sub-indicador de Abastecimento de água (IAB), composto pelas variáveis: frequência do abastecimento, reservação interna e qualidade da água;

- $\quad$ sub-indicador de Esgotamento Sanitário (IES), composto pelas variáveis: destinação dos dejetos (fezes/urina) e destinação das águas servidas (pias, banheiros, lavanderias);

- sub-indicador de Resíduos Sólidos (IRS), composto pelas variáveis: acondicionamento doméstico, destinação do lixo (após acondicionamento), destinação do lixo após coleta e frequência da coleta;

- $\quad$ sub-indicador de Saúde Pública (ISP), composto pelas variáveis: incidência de doenças e frequência do profissional de saúde;

- $\quad$ sub-indicador de Características da Moradia (ICM), composto pelas variáveis: tipo de uso, aglomerações, materiais e cômodos (quantidade);

- sub-indicador de Satisfação com a Moradia e o Entorno (ISME), composto pelas variáveis: percepção do morador e vontade de mudar-se;

- sub-indicador de Espaço Público Comunitário (IEPC), composto pelas variáveis: lazer e situação das vias e calçadas;

- sub-indicador Sócio-Econômico (ISE), composto pelas variáveis: educação e renda.

A Equação 1.1 abaixo foi a utilizada para aferição final do ISA/SAR. Cada peso atribuído a seu respectivo sub-indicador foi assim adotado conforme sua maior influência para a salubridade do local, seguindo ordem de peso por esta importância conforme observado na pesquisa em campo e nos dados coletados.

ISA $/ \mathrm{SAR}=0,10 \mathrm{IAB}+0,25 \mathrm{IES}+0,15 \mathrm{IRS}+0,10 \mathrm{ISP}+0,15 \mathrm{ICM}+0,05 \mathrm{ISME}+0,15 \mathrm{IEPC}+0,05 \mathrm{ISE}$

\section{RESULTADOS E DISCUSSÃO}

A partir do cálculo de cada sub-indicador que compõe o ISA/SAR e de seus consequentes resultados, foi possível estabelecer a Tabela 1.1 com a homogeneização dos mesmos. 
Tabela 1.1 - Homogeneização dos resultados obtidos por sub-indicador do ISA/SAR.

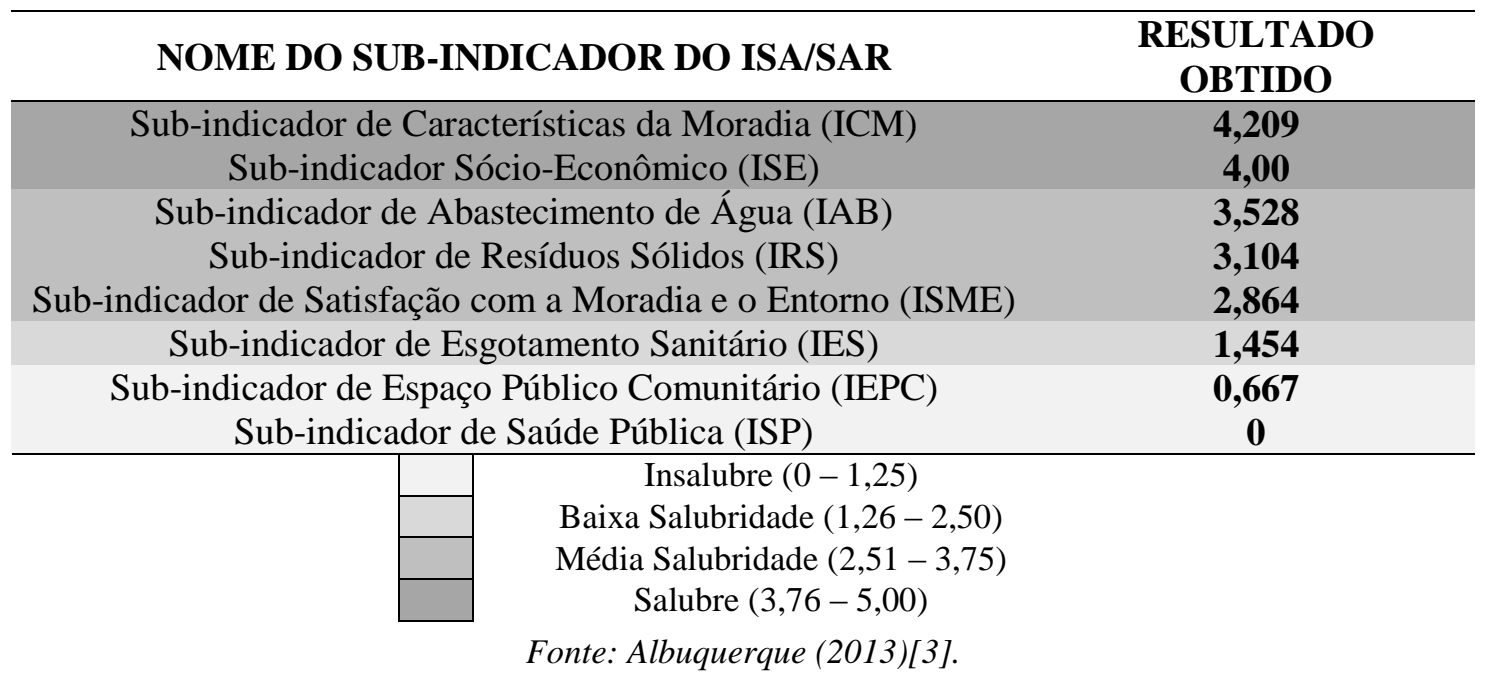

A partir da Equação 1.1 supracitada, o resultado final alcançado foi de 2,256, conforme apresentado na Tabela 1.2.

Tabela 1.1 - Resultado final e faixa de salubridade correspondente ao ISA/SAR

\begin{tabular}{ccc}
\hline Resultado final & Pontuação & Faixa de salubridade \\
\hline \multirow{2}{*}{$\mathbf{2 , 2 5 6}$} & $0-1,25$ & Insalubre \\
& $1,26-2,50$ & Baixa Salubridade \\
& $2,51-3,75$ & Média Salubridade \\
& $3,76-5,00$ & Salubre \\
\hline
\end{tabular}

Fonte: Albuquerque (2013)[3].

Observa-se que, quando corroborados com a faixa de salubridade adotada na pesquisa, os maiores resultados correspondentes ao sub-indicador de Características da Moradia (ICM) e ao sub-indicador de Sócio-Econômico (ISE) apresentam-se como Salubres, seguidos dos resultados do sub-indicador de Abastecimento de Água (IAB), do sub-indicador de Resíduos Sólidos (IRS) e do sub-indicador de Satisfação com a Moradia e o Entorno (ISME) que se encaixam na Média Salubridade. Já o sub-indicador de Esgotamento Sanitário (IES) apresenta um resultado classificado como Baixa Salubridade, e na pior situação, estão os resultados do sub-indicador de Espaço Público Comunitário (IEPC) e do sub-indicador de Saúde Pública (ISP), 0,667 e 0 respectivamente, classificando-os como Insalubres.

Dada suas inadequações, a infraestrutura de saneamento ambiental existente na comunidade se mostra insatisfatória quanto ao atendimento das necessidades de sua população, dando à comunidade uma baixa salubridade, representando um grande impacto negativo sobre a mesma e sobre seu entorno.

Dito isto, apresentam-se a seguir os principais pontos de discussão desta pesquisa observados dentro da cada temática dos sub-indicadores adotados e que se acredita terem sido determinantes para a obtenção dos resultados ora apresentados.

- Em relação à infraestrutura de abastecimento de água:

Evidencia-se que todos os domicílios da amostra pesquisada são atendidos satisfatoriamente pela infraestrutura de abastecimento de água e, talvez por isso, seus habitantes não considerem necessária a existência de reservatório interno nos domicílios, como foi levantado em pesquisa. No entanto, esta inexistência se associada à falta frequente de água que, apesar de ser rara, quando acontece geralmente dura de um a três dias conforme relatos, pode ser um complicador para a saúde da população em geral dada sua importância vital.

Todos moradores pesquisados foram unânimes ao afirmar que consideram a água que chega até suas residências como de muito boa qualidade, qualidade esta confirmada no laudo emitido pelo Instituto Tecnológico de Pesquisas do Estado de Sergipe (ITPS) responsável pela análise 
das amostras de água coletadas no conjunto quanto à presença ou ausência de coliformes totais e termotolerantes.

Neste sentido, evidencia-se que de fato o sub-indicador de abastecimento de água é um dos mais satisfatórios não somente pelo seu cálculo, mas por sua realidade encontrada.

\section{- Em relação à infraestrutura de esgotamento sanitário:}

A totalidade da amostra apresenta o sistema de esgotamento sanitário composto por fossa séptica e sumidouro e que atende de modo satisfatório aos domicílios. Entretanto a destinação de suas águas servidas em sua situação mais comum - as vias -, é um problema bastante grave encontrado e recorrente em todas as vias do conjunto, em maior ou menor quantidade, até mesmo em época de verão.

Esta identificação imputou ao seu sub-indicador correspondente o terceiro valor mais baixo obtido para os sub-indicadores do ISA/SAR, revelando assim sua influência negativa na salubridade da comunidade em geral.

\section{- Em relação à infraestrutura de resíduos sólidos:}

A maior parte dos domiciliados mencionou acondicionar seus resíduos sólidos em suas residências para posterior coleta, porém a realidade mostra que estes se encontravam espalhados por todo o conjunto, principalmente no entorno natural próximo ao trecho da rodovia SE/100 que corresponde a rua $\mathrm{B}$, principal acesso a comunidade. Estes mesmos domiciliados que também demonstraram consciência quanto à presença de lixo no conjunto e na natureza, incidem reclamações sobre os mesmos, mas realizam a deposição inadequada de seus resíduos sólidos.

Nas demais vias do conjunto em si, há presença de resíduos sólidos dispersos em menor quantidade do que no entorno próximo ao conjunto. Isto se deve a presença dos tonéis dispostos nas vias para recolhimento do mesmo, mas que geralmente encontram-se saturados de lixo por vários dias sem a devida coleta a ser realizada pela prefeitura.

O meio ambiente natural está sendo sensivelmente degradado com esta deposição de resíduos e isto pode ser evidenciado em todo seu entorno próximo. Até mesmo sua destinação final após a coleta, de responsabilidade da Prefeitura Muncipal, para uma plantação de coqueiros próximos a um povoado no entorno, atinge a natureza de modo severo e sem que esta tenha a capacidade de absorver tais resíduos.

Outro ponto grave se refere à frequência da coleta de resíduos que evidentemente não é semanal. Este dado foi assim utilizado por ser o oficial informado pela Prefeitura Municipal, mas não condiz com o encontrado em campo. Acredita-se que o retardo na coleta possa estar relacionado à pavimentação irregular e inadequada da única via de acesso ao conjunto do Saramém, a rodovia SE/100 e também a uma falta de estruturação da Prefeitura Municipal quanto à distribuição do atendimento para a demanda de seus povoados e comunidades.

Apesar do sub-indicador correspondente a este tema não ter obtido um dos piores resultados, não se encontra de todo satisfatório, visto que as informações oficiais que foram dadas não corroboraram com a realidade encontrada.

\section{- Em relação à Saúde Pública:}

A incidência de doenças é de certa forma obvia em virtude da situação de baixa salubridade encontrada em campo. No entanto, entende-se que há distorção quanto às informações relacionadas à saúde pública da população da comunidade, fornecidas pela Secretaria Municipal de Saúde de Brejo Grande, e a realidade da mesma. Não há como haver um controle preciso quanto às informações visto que a maioria da população, quando enferma, busca auxílio em outros municípios mais próximos que a sede, a exemplo de Piaçabuçu em Alagoas e do povoado Brejão dos Negros, além de buscar, primeiramente, a ajuda dos agentes de saúde que residem na comunidade.

A frequência do profissional no posto de saúde do conjunto, segundo levantamento e citação da população pesquisada, é bem rara o que corrobora com a frequência mensal citada pela Secretaria Municipal de Saúde. Na grande maioria das vezes, durante o período de pesquisa, o posto de saúde encontrava-se fechado e sem qualquer responsável pelo mesmo o que, segundo os moradores, é muito comum o que os leva a buscar atendimento externo à comunidade. 
O sub-indicador correspondente, o ISP, resultou, portanto, no pior índice encontrado na pesquisa, corroborando com a realidade e diretamente relacionado com demais indicadores conflituosos para a salubridade do local.

\section{- Em relação à Moradia:}

A totalidade dos domicílios levantados contam com abastecimento de água, energia elétrica e sistema de esgotamento sanitário individual (fossa séptica e sumidouro), que atende de modo satisfatório - à exceção da destinação comum das águas servidas.

Praticamente todas as moradias da amostra apresentam uso exclusivamente residencial, sendo o uso misto correspondente em geral a mercearias ou pequenas vendas. Quanto aos materiais, contam com boas condições do piso, do teto e de suas paredes, em sua maioria, o que indica uma boa salubridade interna nas mesmas, reduzindo-se assim a possibilidade da presença de vetores.

À exceção de uma única habitação, todas as demais levantadas têm acima de quatro cômodos que correspondem, geralmente, de três a quatro quartos, uma sala de estar, um banheiro, uma cozinha juntamente com a copa para refeições e sem varandas ou com apenas uma. A construção destas varandas ocorre ocupando quase a totalidade da largura do passeio, impedindo a passagem dos transeuntes. Em geral, a densidade por domicilio é de até três ou até cinco pessoas residindo numa mesma moradia, o que algumas vezes ainda evidencia situação de coabitação, fator este que influencia na salubridade interna das moradias.

Seu sub-indicador foi o de maior valor obtido, indicando boa influencia para a comunidade.

- Em relação à satisfação com a moradia e a satisfação com o entorno:

É praticamente unânime a satisfação do morador com sua habitação, o que corrobora também com sua ausência de vontade em mudar-se da mesma ou do povoado.

A grande maioria dos entrevistados está insatisfeita com a oferta dos serviços de infraestrutura que correspondem ao esgotamento sanitário das águas servidas, juntamente com a má pavimentação das vias e dos serviços de coleta que, ao atrasar, aumentam a presença de lixo em todo o conjunto e em seu entorno.

Do mesmo modo, apresentam-se insatisfeitos com o espaço público comunitário, representados pela praça e pelo campo de futebol oficial do conjunto, devido à falta de pavimentação adequada bem como a inexistência da finalização dos mesmos.

O sub-indicador desta temática foi, portanto um dos indicadores com um dos valores mais baixos obtidos, influenciando assim negativamente para a baixa salubridade da comunidade.

\section{- Em relação ao espaço público comunitário:}

De modo geral, os principais fatores que pesam sobre a salubridade do meio estão intrinsecamente relacionados ao espaço público comunitário, principalmente no tocante às vias existentes na malha do conjunto até mesmo na que dá acesso ao mesmo. Seja a saúde pública que depende destas vias, ou a destinação das águas servidas quando a estas se destinam, a irregularidade da pavimentação ou a falta de conservação e o acúmulo de lixo nas mesmas e até mesmo a insatisfação dos moradores com o serviço de esgotamento sanitário das águas de pias, banheiros, etc, todos estão direta ou indiretamente ligados à problemática das vias do conjunto.

Com exceção de uma única via, foi possível identificar que todas as demais contam com irregularidade em sua pavimentação, e até mesmo com presença de areia e vegetação em boa parte delas. No encontro entre as vias, o acúmulo de águas servidas é ainda mais evidente, além da presença das mesmas também em sua extensão, misturando-se aos resíduos sólidos e animais.

Todas as vias são utilizadas para o trânsito dos próprios moradores e pedestres e não as calçadas. Acredita-se que seja devido, além do costume, à irregularidade da pavimentação das mesmas, bem como a grande presença de varandas que avançam sobre o passeio sem qualquer padrão e respeito ao espaço do pedestre.

Todas as calçadas foram executadas pelos próprios moradores que as veem como uma extensão de sua casa, muitas vezes apropriando-se destas para a construção de tais varandas.

Em relação à pavimentação das calçadas, quando existente, encontra-se geralmente quebrada, quando inexiste, esta só na areia e mato. Ainda assim, quando livres de varandas, também são utilizadas como espaço comum de lazer, seja pra conversas entre vizinhos, brincadeiras entre crianças ou jogos entre adultos. 
O valor obtido pelo sub-indicador correspondente foi o segundo mais baixo obtido, o que corrobora com o observado em campo ora relatado na pesquisa.

- Em relação aos aspectos socioeconômicos:

Existiu ausência de informações acerca da escolaridade da comunidade ou não houve interesse no repasse de tais informações por parte da Secretaria de Educação bem como da Secretaria de Ação Social do município, uma vez que foram realizadas um total de três visitas em cada uma destas para a captação das informações e as mesmas não foram devidamente obtidas. Por isto, utilizou-se de dados da pesquisa de Albuquerque (2009)[2] para o atendimento das variáveis do sub-indicador aqui correspondente.

Em se tratando da renda recebida, os domiciliados da amostra revelaram receber menos um salário mínimo ao final do mês, uma vez que dependem da pesca e esta, muitas vezes, segundo os mesmos, mal rende sua subsistência e de sua família.

Apesar da atividade pesqueira ser essencialmente a atividade predominante da população do Saramém, esta apresenta outras atividades para complementar a renda recebida por semana, a exemplo das cocadeiras - como as próprias mulheres deste ramo se denominam -, da fabricação de redes de pesca tanto por homens quanto por mulheres, da fabricação de artesanatos com a palha do coqueiro e demais matérias-primas da localidade além das próprias vendas ou mercearias que existem em algumas casas.

Boa parte da amostra revelou receber auxílio do governo acumulando, em sua maioria, o Bolsa Família juntamente com o Seguro Desemprego da Pesca. Houve certa dificuldade no acesso a tais informações, pois o receio em ter o registro de que possui mais de um auxílio governamental e perder ambos por isso foi unânime.

O sub-indicador correspondente, o ISE, por sua vez, resultou assim no melhor resultado obtido na pesquisa.

Sabe-se que são diversos os aspectos negativos que incidem no saneamento ambiental da comunidade. Estes e outros tantos necessitam ser estudados para a definição e aplicação das melhores estratégias para se alcançar um nível máximo de salubridade do ambiente da comunidade Saramém que se deseja que tenha e, por conseguinte, de sua população.

\section{CONCLUSÕES E RECOMENDAÇÕES}

Os inúmeros contrastes e carências da comunidade Saramém refletem uma possível desconexão em sua relação de equilíbrio com o meio natural bem como com o próprio ambiente construído, implicando diretamente na saúde do meio e da população deste dependente. A própria inadequação da rede de infraestrutura de saneamento ambiental, aliada a falta de comprometimento dos órgãos para sua regularização e a própria ausência de conscientização dos moradores não apenas caracteriza esta comunidade com traços de insalubridade, como se tornam os principais fatores limitantes para uma boa qualidade ambiental no local. O resultado obtido com a aplicação do ISA/SAR reflete exatamente isto: um ambiente com baixa salubridade.

Esta realidade mostra a necessidade de ações conjuntas entre o Poder Público Municipal e a comunidade, de modo a elencar as melhores estratégias para a construção de políticas públicas eficazes, condizentes com a realidade e suas necessidades, para enfim haver a resolução ou a minimização da problemática ambiental que se apresenta no Saramém.

Para a devida análise do cenário levantado, apresentam-se a seguir algumas considerações a respeito do mesmo, com o objetivo não de esgotar o tema, visto que este se porta como uma rica fonte para futuros estudos, mas sim com intenção de promover a discussão do mesmo e, principalmente, dar viabilidade às propostas ora elaboradas. São elas:

- Toda e qualquer ação por parte do Poder Público Municipal nesta comunidade deverá ser precedida da elaboração e priorização de ações de educação ambiental realizadas continuamente com a população de modo a permitir o esclarecimento da mesma quanto suas ações sobre o meio ambiente em que vive e depende e o reflexo destas;

- É vital uma maior e melhor atuação do Poder Público Municipal e Estadual para a devida minimização dos problemas encontrados; 
- Urge a criação de uma Secretaria de Infraestrutura por parte do Poder Público Municipal uma vez que esta inexiste atualmente, sendo suas responsabilidades dispersadas na Prefeitura Municipal. Esta nova secretaria teria entre suas atribuições o dever da fiscalização para o correto cumprimento da oferta dos serviços de infraestrutura e da manutenção dos mesmos em todas as comunidades do município, ação imprescindível na Gestão Pública como um todo que se quer de fato uma administração sustentável e saudável para o meio ambiente e sua população;

- Sugere-se também a priorização dos serviços de coleta de resíduos sólidos, uma maior frequência nos mesmos e uma maior atenção quanto sua destinação final, reafirmando a necessidade iminente da viabilização de um aterro sanitário para o município como um todo;

- Compreende-se como urgente priorizar as ações relacionadas às vias e aos passeios do conjunto, principal agravante da salubridade neste, acima já citadas, mas principalmente seu devido nivelamento e pavimentação além da execução de um sistema de drenagem de águas pluviais posteriormente ao encaminhamento das aguas servidas das residências para seu sumidouro;

- Indica-se também como ação prioritária a execução adequada da pavimentação do trecho da SE/100 de Brejão dos Negros até o Saramém visto que por ser sua única e principal via de acesso, esta necessita estar adequada para solucionar a dificuldade de chegada à comunidade.

Tais recomendações devem, evidentemente, ser amplamente discutidas com a população e entre esta e o Poder Público Municipal, pois sendo interesse de sua gestão ou não, é imperativo o direito a um ambiente saudável e é de sua responsabilidade zelar para que cada comunidade, povoado, município ou cidade tenha este e vários outros direitos assegurados. Espera-se obter assim a real possibilidade de aplicação de novas estratégias para a manutenção da saúde do meio e da população na comunidade Saramém bem como nas demais comunidades rurais, de modo a criar demais iniciativas regionais que possam servir de subsídio para a expansão e a aplicação da sustentabilidade em nível local - quem sabe mundial - e assim se assegurar uma vida plena e de qualidade, em respeito ao meio ambiente.

Tal pesquisa buscou também servir como incentivo para demais estudos futuros nesta e em demais comunidades, servindo como instrumento de análise e principalmente de planejamento para a resolução de problemas voltados a área do saneamento ambiental na área rural, uma área reconhecidamente carente quanto a este tipo de investigação.

Assim, busca-se contribuir para uma boa qualidade de vida da população bem como de seu ambiente natural e construído, de modo a criar caminhos viáveis para se promover a aplicabilidade da proposta do desenvolvimento sustentável: equilíbrio, racionalidade e respeito à natureza.

\section{AGRADECIMENTOS}

Ao Programa de Pós-graduação em Desenvolvimento e Meio Ambiente da Universidade Federal de Sergipe (PRODEMA/UFS) e à Agência CAPES, sem os quais a dissertação de mestrado na qual este artigo se baseia não seria possível.

\section{REFERÊNCIAS BIBLIOGRÁFICAS}

1. Afonso, CM. Sustentabilidade: caminho ou utopia?. São Paulo: Annablume; 2006. 74p. [Português]

2. Albuquerque, MM. Diagnóstico sobre sustentabilidade em comunidades pesqueiras ribeirinhas: o caso Saramém - Brejo Grande/SE [graduation]. Aracaju(SE): Universidade Tiradentes; 2009. 126p. [Português]

3. Albuquerque, MM. Indicador de Salubridade Ambiental (ISA) como instrumento de análise da salubridade do ambiente da comunidade Saramém em Brejo Grande(SE) [dissertation]. São Cristóvão(SE); 2013. 174p. [Português]

4. ALMEIDA, MAP de; ABIKO, AK. Indicadores de salubridade ambiental em favelas localizadas em áreas de proteção aos mananciais: o caso da favela Jardim Floresta. São Paulo: EPUSP, 2000. Disponível em: 〈http://alkabiko.pcc.usp.br/artigos/BT264.pdf〉. Acesso em: 24 set. 2012. 
5. BATISTA, MEM; SILVA, TC da. O modelo ISA/JP - Indicador de performance para diagnóstico do saneamento ambiental urbano. Engenharia Sanitária e Ambiental, Rio de Janeiro, v.11, n. 1, jan./mar. 2006, p.55-64. Disponível em: 〈http://www.scielo.br/pdf/esa/v11n1/29138.pdf>. Acesso em: 24 set. 2012.

6. DIAS, MC. Índice de salubridade ambiental em áreas de ocupação espontânea: estudo em Salvador, Bahia. Dissertação (Mestrado em Engenharia Ambiental Urbana)- Escola Politécnica, Universidade Federal da Bahia, Salvador, 2003.

7. MENEZES, GO de. Aplicação do Índice de Salubridade Ambiental em comunidades carentes e sua comparação com comunidades padrão: instrumento para planos de gestão municipal. Ouro Preto. Dissertação (Mestrado em Engenharia Ambiental)- Universidade Federal de Ouro Preto (UFOP), 2007.

8. Oliveira, MVC; Carvalho, ARde. Princípios básicos do saneamento do meio. 9. ed. São Paulo: SENAC São Paulo; 2007.400p. [Português].

9. Sachs, Ignacy. Caminhos para o desenvolvimento sustentável. Rio de Janeiro: Garamond; 2000. 96p. [Português] 